\title{
OS MURMÚRIOS DE UMA VIVÊNCIA: A DESMITIFICAÇÃO DE UMA IDENTIDADE
}

Raquel Trentin Oliveira ${ }^{\star}$

O trabalho "Os murmúrios de uma vivência: a desmitificação de uma identidade", como parte da linha de pesquisa "Literatura e História" concentrada no estudo de "Literatura e identidade", tem como objeto de análise o texto A Costa dos Murmúrios (1988) da escritora portuguesa contemporânea Lídia Jorge. O trabalho tem o objetivo de observar como o romance de Lídia Jorge contrapõe dois modos de narrar e, a partir desses, constrói diferentes/complementares sentidos para um passado histórico. O conflito entre esses sentidos instaurado no texto processa a remodelação de esquemas feitos, de imagens postas.

Lídia Jorge, nascida no Algarve, em 1946, ocupa um destacado lugar no panorama da literatura portuguesa contemporânea. É considerada, pelos críticos em geral, como uma das mais importantes revelações da ficção portuguesa das últimas décadas: "Lídia Jorge é o maior prodígio das letras pátrias neste

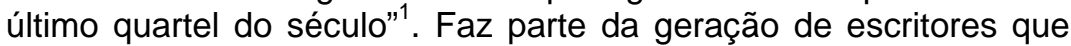
despontaram literariamente com a eclosão revolucionária do 25 de Abril de 1974 em Portugal, momento em que findou a repressão salazarista. Nesse tempo de rupturas, uma crise de identidade abate os portugueses que buscam saber quem são, saber o que lhes resta; altera-se, assim, a imagem ideal da pátria e de si mesmos. Para Maria de Lourdes Netto Simões, que analisa a ficção de autores contemporâneos portugueses em As raízes do imaginário ${ }^{2}$,

O imaginário, resultante das vivências, ficcionaliza-se em enriquecidas interpretações. A retomada da história pela ficção acontece por fixação nos tempos recentes ou nos antigos, muito em consonância com essas vivências de cada um. As experiências de guerra, de repressão, de discriminação, de insegurança, de conquistas, de ganhos e perdas sociais, de angústias povoam o imaginário desses escritores que viveram em Portugal, nas colônias ou no estrangeiro. (p. 233) 
Fruto desse contexto, Lídia Jorge, em suas obras, segundo suas próprias palavras, propõe-se a introduzir um olhar de deformação no "destino oficial da História". A leitura de algumas obras da autora, como O Dia dos Prodígios (1980), O Cais das Merendas (1982), Notícia da Cidade Silvestre (1984), O Vale da Paixão (1998), desvela um texto que problematiza a formação de um novo espaço social português, em que se busca construir outras referências, a partir da crítica à forma romanesca que privilegia modos de ver tradicionais. O narrar, nesses textos, diferente de uma linguagem que se pretende unívoca, é uma aventura errante em que as vozes procuram encontrar um sentido para suas existências.

A costa dos murmúrios, por sua vez, considerado o romance mais célebre de Lídia Jorge, tematiza a guerra colonial em Moçambique e seus efeitos, guerra essa que levaria ao colapso do Estado Novo em Abril de 1974. O enredo encena a mudança de perspectiva sobre os fatos históricos, a avaliação distanciada do acontecido. Para explicar o enfoque dado, alude-se à voz da própria autora: em A costa dos murmúrios,

o que acontece é que Eva Lopo, que é o personagem que dá a história, é uma mulher saída dos anos sessenta que tem uma descrença enorme em relação à História. [...] Entende Eva Lopo que a História é uma mistificação, uma ficção perfeita a partir do real, e que só a ficção se aproxima da realidade. [...]. Eva Lopo sente duas coisas: por um lado a transitoriedade de tudo; os pensamentos não se apanham e o sofrimento não se retém, a História não pode conter o sofrimento individual. Por outro lado, ela tem a consciência de que, ao não recolherem a sua própria História, os Portugueses colaboram com a vocação do correr de tudo que é acabar no desaparecimento. ${ }^{3}$

O texto de Lídia Jorge defende, assim, que a memória, ao retornar no tempo, resgata os murmúrios, os sopros que restam de uma vivência. Antes do Nada se impor, tenta resgatar as vozes que estão à beira de extinguirem-se. Atenta-se, portanto, para o fato de que é necessário testemunhar, falar, rasgar o silêncio para que os acontecimentos não deixem de existir.

O romance está divido em dois relatos. O primeiro apresentase em forma de conto intitulado Os gafanhotos, mantendo, num primeiro plano, as unidades de ação, de tempo e de espaço. Os 
fatos narrados aconteceram há vinte anos: "Rodavam, rodavam os pares. Foi há vinte anos, e ainda não era hábito os pares dançarem desenlaçados..." (p. 11). O relato conta, pela voz de um narrador em terceira pessoa, dois dias de história em trinta páginas de narrativa, que têm como ação principal a comemoração do casamento de Evita e do alferes Luís Alex por militares portugueses e suas famílias. A festa se dá no terraço do Hotel Stella Maris, na cidade da Beira, Moçambique, no continente africano, ainda sob o domínio político de Portugal. A comemoração representa assim uma trégua na luta para o sufocamento dos levantes pela independência que continuam no interior da colônia. No contexto do feliz casamento, em que se vive "um estremecimento de gáudio e furor", a guerra fica em segundo plano, evocada, principalmente, no diálogo dos soldados portugueses, participantes da festa. As mortes, massacres, pragas aconteciam "naturalmente" e a guerra era "uma rebelião de selvagens".

A organização dos acontecimentos no conto explicita regularidade e linearidade na ordem de distribuição dos fatos na narrativa. O casamento de Evita e do alferes começa a ser flagrado em uma tarde - "ainda era de tarde" (p. 11) - em que as principais ações da festa do casamento se passam no terraço do hotel Stella Maris. Um passeio do casal pela costa é determinado no fim da tarde e no início da noite - "o fim do dia era demais" (p. 15). A volta ao hotel culmina com o escurecer - "começava a fazer escuro total" (p. 16) -, em que aparecem inúmeros cadáveres de negros moçambicanos à beira-mar, os quais estavam sendo carregados por "dumpers". Segundo a explicação que circula, os negros haveriam arrombado um carregamento de metanol e ingerido álcool metílico pensando tratar-se de vinho. Enquanto isso, a noiva em seu quarto dorme enquanto a "manhã ameaçava romper a oriente" (p. 17). No terraço, "já tinha evaporado a incerta luz da madrugada, já era de manhã, o cortejo olhava para a barra" (p. 18). A descida do cortejo ao hall para contar os mainatos que faltavam se dá na "luz do dia" que "inundava tudo com uma claridade cruel" (p. 22). Entretanto "aquilo era Domingo, o tempo era amplo, como sempre compete ao Domingo, poderiam regressar todos ao terraço, pedir ao gerente que mandasse servir lá em cima o almoço, e se possível o jantar..." (p. 24). Os noivos, que até então permaneciam no quarto, onde "acordavam e dormiam", "subiram para a tarde, emagrecidos, e só havia passado um dia [...] De facto, o Sol tinha feito o seu giro e estava na posição em que de véspera o tinham encontrado..." (p. 
26). A festa recomeça restabelecendo o tempo vivido no dia anterior, numa tarde que "desaparecia quente e clara..." (p. 28), que "punhase tão bem" (p. 29) enquanto "os dumpers de novo se enchiam de gente" (p. 29). "E a noite iria cair em breve, cair vermelha e negra como um tapete..." (p. 31), e "de repente as luzes acenderam-se" (p. 32 ), entretanto foram ofuscadas por uma chuva de gafanhotos. $\mathrm{Na}$ "obscuridade do terraço" (p. 35), adentra um repórter. E é na noite verde - "verde toda a noite" - que o alferes Luís Alex intervém contra a entrada do jornalista, considerada inadequada pelos militares. A Evita resta "abeirar-se dele, lavar-lhe o buraco da testa por onde a bala havia entrado e beijá-lo na boca até ser manhã" ( $p$. 38).

Nota-se, portanto, que os instantes temporais estão minuciosamente marcados sendo que os seus limites correspondem a limites de ação e de espaço. Assim, os principais acontecimentos concentram-se na noite e no terraço. Por conseguinte, a forma do conto constrói uma moldura para os fatos recordados, que, num primeiro plano, imprime uma visão una, íntegra, fechada aos acontecimentos.

Já o segundo relato da narrativa é coordenado pela voz de Eva Lopo, a noiva Evita vinte anos depois. Abre-se a narração com um comentário de Eva sobre o conto Os gafanhotos que acabara de ler. Reflete, a partir dele, sobre a relações entre história, memória, representação dos fatos vividos. Sua narração, ativada pela leitura do conto, tem como interlocutor o autor d'Os gafanhotos: "Para o escrever desse modo, deve ter feito...". O relato de Eva flagra os mesmos acontecimentos evocados no conto, que perdem a forma sintética e condensada, e surgem extensos, diluídos nas lembranças da narradora. As unidades de ação, de espaço e de tempo enfraquecem, e o passado vem à tona fragmentado, suscitando comentários e impressões afetivas da narradora que sobrepõem ao tempo pretérito, vivido por Evita, as marcas do presente de Eva. O testemunho de Eva Lopo, que se pretende "mais próximo ao real", apesar de consciente da infidelidade das lembranças, busca desmascarar os fatos do conto. Ao contrário do capítulo inicial, Eva não dá qualquer relevo à festa do casamento. O jornalista que, n'Os gafanhotos, só é mencionado no fim como um invasor do terraço do Hotel, no relato de Eva Lopo, recebe nome, Álvaro Sabino, e tornase amante de Evita. É ele, segundo Eva Lopo, que guardou as imagens de memória narradas no conto: "O jornalista contou-Ihe. De outra forma, como poderia ter imaginado com tanta precisão a sua 
chuva?" (p. 247). O alferes Luís torna-se então uma sombra do seu capitão e a sua construção sugere como o sucesso da doutrinação ideológica resulta na obsessão de se tornar um herói de guerra, capaz de cometer atos de uma violência desumana. As mulheres deixam de ser apenas uma parte do cenário, como no conto, e as suas vidas ganham importância enquanto, convivendo com o vazio e a falta de objetivos, esperam, no hotel, os seus maridos voltarem da batalha. Evita descobre outra versão para as mortes do envenenamento e tem acesso a fotos, guardadas como segredos militares "TO BE DESTROYED", que revelam as atrocidades da luta. Enfim, evidencia-se que a guerra contamina todas as atividades, até mesmo o amor. Na narração de Eva Lopo, portanto, os fatos perdem o véu da forma que encobre a violência, a crueldade, a dor que marcam a experiência da guerra e o falar desta. Assim, os relatos obedecem a uma estrutura de avanço e recuo, que, no diálogo, constroem um sentido complexo, híbrido, para o testemunho do conflito colonial.

Frente a tal narrativa, algumas questões de análise se impõem: como a mesma matéria factual pode adquirir diferentes significados em duas maneiras de recordar? Qual o modo de narrar encenado em Os gafanhotos e no relato de Eva Lopo? Que funções assumem os dois narradores? Como se faz a reconstituição do tempo e do espaço na memória dos narradores? O sentido do relato de Eva Lopo anula o sentido de Os gafanhotos? Como se representa a diferença, o outro no texto? Como a narrativa impõe a reflexão/desmitificação da identidade portuguesa? De que forma a metaforização literária ilumina a designação histórica?

A análise da fortuna crítica de Lídia Jorge aponta para abordagens centradas no comportamento do narrador, na relação ficção/história encenada pela metaficção historiográfica, na construção da identidade a partir da dialética do mesmo e do outro. Nota-se que o ponto unificador dos olhares é a relação crítica que o texto estabelece com a História. No entanto, observa-se, como reclama Paulo de Medeiros em seu artigo Memória Infinita, no qual reflete sobre A costa dos murmúrios, que, "ao insistir tanto na História, o que a crítica tem descuidado é uma consideração séria do papel da memória, quer na sua relação com a história quer em termos teóricos. Isto porque a memória não pode ser encarada como simples meio de re-escrever ou contestar a História" (p. 63, 1999). Para o crítico, a memória, mesmo que pessoal e múltipla, não pode ser vista como simples termo de oposição ao discurso da 
História. Os textos críticos lidos apontam para Os gafanhotos como um modelo do discurso autoritário da História que se contrapõe à memória de Eva Lopo. No entanto, como confirma Medeiros, em si mesmo ele já é constituído pela memória. O narrador de Os gafanhotos recorda-se, apesar de não deixar explícito o seu processo de rememoração: "Rodavam, rodavam os pares. Foi há vinte anos, e ainda não era hábito..." (p. 11). Eva Lopo define Os gafanhotos como memória quando reflete sobre o ato de narrar do jornalista: "Para escrever desse modo, deve ter feito uma viagem trabalhosa a um tempo onde qualquer outro teria dificuldade em regressar" (p. 41). Tenta-se, portanto, atendendo ao que reclama Medeiros, encarar o texto de Lídia Jorge como a recusa da oposição memória x história.

A própria autora, em entrevista a Álvaro Cardoso Gomes, afirma que o que pretendeu em $\mathbf{A}$ costa dos murmúrios foi criar

dois momentos da memória, de duas memórias diferentes [...] No fundo, tive a intenção de que esse confronto entre duas visões desse a impressão de que é impossível reconstituir a vida, de que é impossível reconstituir o comportamento da memória. E, sobretudo, que a história é uma ciência falsa face à reconstituição do passado. O passado só se consegue reconstituir, na medida do possível, através das memórias. (Lídia Jorge, 1993).

Em outras palavras, a autora afirma que contar o passado depende da memória; que fazer história implica fazer memória. Helder Macedo confirma essa visão quando, em um ensaio intitulado Telas da memória, escreve que "o que chamamos de História é também uma percepção de memória [...] A História nunca é aquilo que aconteceu mas aquilo que permite significar o que aconteceu" (2002, p. 38 ).

O que diferencia o relato do jornalista e o relato de Eva Lopo é que a memória do primeiro seleciona o que quer contar e tenta apagar o que quer esconder; enquanto que a memória de Eva Lopo irrompe fragmentária, conduzida pela lembrança dos acasos cotidianos testemunhados. Acasos que marcam sua vida pessoal, mas que se ligam aos acontecimentos históricos da guerra colonial.

A narração de Eva Lopo coloca em evidência, portanto, uma representação de memória enquanto impossibilidade de 
reconstituição fiel do passado, enquanto incapacidade de reconstruir fatos unos e tempos lineares.

Dessa forma, o ato de contar a "experiência vivida" pela memória encenado em A costa dos murmúrios exige que se faça uma reflexão sobre os textos O narrador (1969) e Sobre Alguns temas em Baudelaire (1962) de Walter Benjamin, os quais discutem o papel do narrador em um momento em que o sentido da "experiência compartilhada" perdeu o seu valor, e são lançadas as formas para um novo narrar. Essas formas, segundo Benjamin, ligam-se à experiência estética de Proust que reflete sobre a existência de memórias no plural. Para o autor, temos duas memórias: uma, a memória voluntária, é ativada pelo hábito, pela repetição, pelo esforço intelectual; outra, a involuntária, é evocada pelos sentidos, pelas sensações que não foram conscientemente vividas e que facilitam recriar no presente uma imagem do passado.

Em O narrador, Walter Benjamin afirma que "perdemos a capacidade de trocarmos pela palavra experiências", o ato de narrar entra em crise no momento em que "as experiências perderam em muito o seu valor". A passagem pela Guerra foi um marco nesse sentido, pois ao seu final "os indivíduos voltaram emudecidos aos seus lares". O homem já não conhece o ato de contar histórias, de aconselhar, "extingui-se o lado épico da verdade, a sabedoria" da qual eram os portadores principais os velhos, que transmitiam de geração a geração os ensinamentos da experiência. Ao traço característico da narrativa, do gênero épico, a transmissão oral, a idade moderna sobrepõe o romance, que não procede da tradição oral e nem a provoca. Assim o romance, fechado na forma do livro, tem como local de origem o "indivíduo na sua solidão" que não sabe transmitir "conselhos de qualquer natureza" e que se firma sobre o "incomensurável na representação da vida humana". Enquanto a memória épica, concretizada na invocação às musas, é dedicada a um herói, a uma viagem aventurosa ou a uma luta, a memória do romancista consagra-se a muitos eventos esparsos.

O texto Sobre alguns temas em Baudelaire sugere posições possíveis para o narrador moderno. Para Benjamin, frente ao esfacelamento da memória e da experiência enquanto tradição compartilhada, Proust, em sua obra literária, "dá uma idéia das operações necessárias para reintegrar ao presente a figura do narrador" (p. 37). No conceito de mémoire involontaire de Proust, Benjamin ressalta a crítica à memória voluntária: "O mesmo vale para o nosso passado. Em vão tentamos reevocá-lo; todos os

fragmentum, nº 8. Laboratório Corpus: UFSM, 2004. 
esforços do nosso intelecto são inúteis". Para Proust, segundo Benjamin, o passado "está fora do seu poder e de sua alçada, em qualquer objeto material (ou na sensação que tal objeto provoca em nós) que ignoramos qual possa ser. Encontrar ou não esse objeto antes de nossa morte depende unicamente do acaso" (p. 37). Proust deixa notar a dificuldade de contar, em sua própria obra, o passado, uma vez que esta possibilidade dependeria do acaso. Dessa forma, a memória involuntária, segundo o crítico alemão, pertence ao "repertório da pessoa particular isolada em todos os sentidos. Onde há experiência, no sentido próprio do termo, determinados conteúdos do passado individual entram em conjunção, na memória, com os do passado coletivo". Assim, o acaso pode estimular as correspondances observadas por Proust na obra de Baudelaire: "Em Baudelaire, escreve Proust, o tempo é dividido de modo desconcertante; somente se revelam poucos dias, e apenas dias significativos" (p. 53). Para Benjamin, o conteúdo desses "dias de lembrança" foi fixado por Baudelaire no conceito de correspondances. Dessa forma, a memória involuntária de Proust, evocada pelo acaso, contra a memória uniforme voluntária, surgiria instável e descontínua, deixando vir à tona os vazios, as lacunas e as dimensões afetivas que a coordenam.

A análise feita por Gérard Genette sobre a obra de Proust, no texto Discurso da Narrativa, deixa entrever essa relação quando o autor destaca a reminiscência proustiana como "êxtase, 'duração dum relâmpago', miraculosa síncope, 'minuto resgatado da ordem do Tempo'" (p. 222). O processo de narração de Marcel, narrador e protagonista da obra Em busca do tempo perdido de Proust, é "instantâneo". O tempo, segundo Genette, surge fragmentado, recheado de recuos e avanços temporais. A história apresenta-se em sua duração, em progressão, enquanto a narrativa se concretiza em sua simultaneidade. A narrativa pretende-se mimética, próxima ao real, mas permite visualizar os rastros de quem a organiza. A relação afetiva comanda a reminiscência do narrador-protagonista; o narrador ultrapassa a sua função de apenas contar a história, refletindo sobre o vivido, relacionando diferentes tempos.

Aproximando-se da forma proustiana de narrar, a posição assumida pela narradora de A costa dos murmúrios apresenta uma concepção de memória que leva em conta a dificuldade de se reconstruir o passado e de compartilhar a experiência: "uma memória fluida é tudo o que fica de qualquer tempo, por mais intenso que tenha sido o sentimento, e só fica enquanto não se 
dispersa no ar" (Jorge, 1988, p. 42). Eva Lopo, a narradoraprotagonista do romance, em suas lembranças, busca reconstruir um passado que se revela esparso, fragmentário, escorregadio. A representação do tempo pretérito está sujeita aos acasos do presente: "O Stella, que não é outra coisa mais do que esse fulgor que estoira de ano a ano, de biênio em biênio, a propósito de um cheiro ou de uma carta, será enterrado pouco a pouco, aos pedaços, a medida que a geração que o viu suspire e acabe" (Idem, p. 209). Os fatos surgem instantâneos, sem que haja uma lógica causal ligando-os: "o que você nota não são as causas e os efeitos mas soberbas simultaneidades" (Idem, p. 178); "Há porém um momento em que um reflexo acontece e ilumina um pouco da sombra que avança silenciosa, sem ruído... (Idem, p. 256). O passado dialoga com outros tempos, é recheado pelo presente, evoca situações futuras. As lembranças surgem moldadas à emoção da narradora. A narração concretiza-se na relação afetiva que liga a voz narrante com as suas próprias experiências na busca de lembranças significativas que permitam as correspondências: "Aconselho-o porém a que não se preocupe com a verdade que não se reconstitui, nem com a verossimilhança que é uma ilusão dos sentidos. Preocupe-se com a correspondência" (Idem, p. 42).

A experiência vivida individualmente evoca uma história coletiva marcada pelo silêncio da experiência da guerra, a narradora mostra-se consciente da dificuldade de reconstruir esse tempo, mas de igual forma, atenta para a necessidade de verbalizá-lo, dessa maneira resgatando-o do silêncio, do esquecimento: "alguma vez se perde a memória do que desejamos [...] então se nos fôssemos esquecendo do que desejamos descobrir, e depois do que nos chamávamos, e a seguir de que país éramos, como iríamos combinar as horas de sair, ou o momento de fazer compras [...] claro que tudo isso andava ligado por uma tênue linha que de repente poderia quebrar, e que apesar de ser tão tênue, ainda permitia uma pequena correspondência de modo a não boiarmos à face da terra como lama..." (Idem, p. 47). Da mesma forma, Eva Lopo, ultrapassando sua função de apenas contar os fatos, assume um papel crítico, refletindo sobre o passado, do presente, para construir um futuro: "vejo sombras [...] evite todas as sombras. Tem-se feito um esforço enorme ao longo desses anos para que todos nós o tenhamos esquecido. Não se deve deixar passar para o futuro nem a ponta duma cópia, nem a ponta duma sombra" (Idem, p. 136). 
Atendo-se mais especificamente à forma de interlocução que se encena em A costa dos murmúrios, nota-se que há dois testemunhos: o do jornalista e o de Eva Lopo. Sobre ambos os textos paira a voz de um narrador heterodiegético, ausente à história contada, que, em Os gafanhotos, imprime sobre o testemunho do jornalista a forma sintética, linear e objetiva do conto - "Não utilize a visão do jornalista para pôr fim à sua narrativa verdadeira. Fez bem não utilizar. Eu compreendo que vinte anos depois ele tenha guardado essa visão na memória. Compreendo que ele desejasse que assim tivesse sido [...]. Foi isso que ele lhe contou?" (Idem, p. 247) - e, no segundo relato, posiciona-se, como um interlocutor que ouve e apenas cumpre a função de registrar o que "disse Eva Lopo", deixando que a narração desta tome o primeiro plano.

A narrativa constrói-se, assim, no diálogo entre duas memórias sobre um mesmo fato. A memória primeira se aproxima do sentido que assume a memória voluntária, a qual se pretende contínua, uniforme. Mas, como ensina Proust, no primeiro volume de Em busca do tempo perdido, No caminho de Swann, opera com imagens que, apesar de representarem a vida, não guardam nada dela: "Na verdade, poderia responder, a quem me perguntasse, que Combray compreendia outras coisas mais e existia em outras horas. Mas como então o que eu recordasse me seria fornecido unicamente pela memória voluntária, a memória da inteligência, e como as informações que ela nos dá sobre o passado não conservam nada deste, nunca me teria lembrado de pensar no restante de Combray" (1987, p. 48). A memória voluntária representa, nesse sentido, um esforço vão na reconstituição do passado: "Trabalho perdido procurar evocá-lo, todos os esforços da nossa inteligência permanecem inúteis" (1987, p. 48). Ainda na mesma obra, é a memória involuntária, despertada pelos sentidos, que possibilita o resgate da dimensão afetiva e descontínua do passado:

Mas quando mais nada subsiste de um passado remoto, após a morte das criaturas e a destruição das coisas, sozinhos, mais frágeis porém mais vivos, mais imateriais, mais persistentes, mais fiéis, o odor e o sabor permanecem ainda por muito tempo, como almas, lembrando, aguardando, esperando, sobre as ruínas de tudo o mais, e suportanto sem ceder, em sua gotícula impalpável, o edifício imenso da recordação. (Proust, 1987, p. 51) 
Por seu lado, Eva Lopo, em seu relato, parece acusar o narrador de Os gafanhotos de representar uma verdade compacta, una, mas distante do real:

Definitivamente a verdade não é o real, ainda que gêmeos, e n'Os gafanhotos só a verdade interessa. Por isso não teria sido útil introduzir o gesto do alferes [...] as curiosidades que Ihe conto, estas imperfeitas lembranças, se não conduzem à demostração da verdade deslumbrante d'Os gafanhotos, serão tão inúteis [...] a verdade deve estar unida e infragmentada, enquanto o real pode ser - tem de ser porque se não explodiria - disperso e irrelevante, escorregando literalmente, como sabe, para local nenhum. (Jorge, 1988, p. 85)

São as lembranças evocadas pelo acaso de um acontecimento exterior, a leitura de Os gafanhotos - "o seu relato foi uma espécie de lamparina de álcool que iluminou durante esta tarde, um local que escurece de semana a semana, dia a dia, à velocidade dos anos" (p. 42) - que permitem a redescoberta de um tempo que se esvai. Diz Eva Lopo ao narrador do conto, referindose à imagem de Evita construída por este: "agora vejo-a, por sua ação, atravessando o hall do Stella Maris, e fico com algum apreço por ela, e tenho mesmo saudade dela...." (p. 44).

Finalmente, o que se coloca em confronto em A costa dos murmúrios são duas formas de se contruir a memória, uma que pretende comunicar o conhecimento do passado, como verdade una, encerrada em um tempo fechado, na forma do conto; e outra que busca, pela rememoração, reconstruir o real e, nesse sentido, age tecendo "tênues" fios entre os homens, os lugares, os tempos presente, passado e futuro, tal como a narrativa de Eva Lopo. A costa dos murmúrios, assim, pela rememoração, recria o passado a partir das necessidades do presente e projeta o futuro. Finalmente, as palavras de Jacques Le Goff em História e Memória podem iluminar o fechamento deste ensaio: "a memória, onde cresce a história, que por sua vez a alimenta, procura salvar o passado para servir o presente e o futuro" (p. 477).

NOTAS

fragmentum, n 8. Laboratório Corpus: UFSM, 2004. 
* Aluna do Programa de Pós-Graduação em Letras - Nível Mestrado - da Universidade Federal de Santa Maria. Membro do Laboratório Corpus.

${ }^{1}$ SIMÕES, João Gaspar. Diário de notícias.

${ }^{2}$ SIMÕES, Maria de Lourdes Netto. As raízes do imaginário, 1990, p. 233.

${ }^{3}$ Excerto da entrevista de Lídia Jorge a Inês Pedrosa publicada na revista Ler. Livros \& Leitores, 1988.

\section{REFERÊNCIAS BIBLIOGRÁFICAS}

BENJAMIN, Walter. O narrador. In: BENJAMIN, W.; HORKHEIMER, M.; ADORNO,T.; HABERMAS, J.; Textos Escolhidos. Os pensadores. São Paulo: Abril Cultural, 1975.

Sobre alguns temas em Baudelaire. In: BENJAMIN, W.; HORKHEIMER, M.; ADORNO,T.; HABERMAS, J.; Textos Escolhidos. Os pensadores. São Paulo: Abril Cultural, 1975. GENETTE, Gerárd. Discurso da narrrativa. Lisboa: Vega, 1976. GOMES, Álvaro Cardoso. A voz itinerante. São Paulo: EDUSP, 1993.

JORGE, Lídia. O dia dos prodígios. Lisboa: Dom Quixote, 1980. . O cais das merendas. 5. ed. Lisboa: Dom Quixote, 1995.

1994. . Notícia da cidade silvestre. 10. ed. Lisboa: Dom Quixote,

. A costa dos murmúrios. Lisboa: Dom Quixote, 1988.

O vale da paixão. Lisboa: Dom Quixote, 1998.

LE GOFF, Jacques. História e memória. Campinas: Unicamp, 1996.

MACEDO, Helder. As telas da memória. In CARVALHAL, Tânia Franco; TUTIKIAN, Jane (orgs.). Literatura e história: três vozes de expressão portuguesa. Porto Alegre: UFRGS, 1999.

MEDEIROS, Paulo de. Memória infinita. Portuguese literary and cultural studies, n. 2, 1999, p. 61-77.

PROUST, Marcel. No caminho de Swann. Trad. Mário Quintana, 11. ed. Rio de Janeiro: Globo, 1987.

SIMÕES, Maria de Lourdes Netto. As razões do imaginário. Salvador: FCJA; UESC, 1998. 